\title{
Effect of age on fixed and labile components of airways resistance in asthma
}

\author{
MARGARET I. BLACKHALL ${ }^{1}$ \\ Institute of Child Health, University of Liverpool, Alder Hey Children's Hospital, Liverpool
}

\begin{abstract}
The lability index has been used to classify asthmatic subjects into three physiologically distinct groups and provide indices of the fixed and labile components of airways resistance. This classification was used to examine two series of asthmatics (A and B) in order to determine the effect of age on bronchial lability. The mean follow-up period was five years in series $A$ and 18 years in series B. In series A the lability index had been measured previously and changes in value over a period of years were observed. Series B had been carefully assessed on clinical grounds in childhood, and from the case histories obtained then it was possible to determine the severity of the original symptoms and to compare them with the situation at follow-up when the lability index was measured.

Results show that the labile component decreases with age but remains persistently abnormal in some subjects despite the absence of symptoms of asthma. The fixed component remains or increases with age. Thus highly labile asthmatic subjects (called group 2) have the best chance of improvement, while those subjects in whom the fixed component of airways resistance predominates (called group 3 ) are likely to remain in this group and have persistent symptoms.
\end{abstract}

It has been shown that airways resistance in the asthmatic has a labile and a fixed component (Jones, 1966); the former is probably due primarily to bronchiolar muscular constriction and the latter to mucosal swelling and luminal obstruction. Jones used the lability index as a measure of the labile component and suggested a classification (see below) based upon separation of labile and fixed components. All asthmatics are abnormally labile, and while bronchodilator drugs and disodium cromoglycate temporarily reduce the labile component (Jones, Wharton, and Buston, 1963 ; Blackhall and Jones, 1969), steroids reduce the fixed but not the labile one.

There is no close correlation between symptomatology and lability. The reason for this is that lability measures the potential for bronchoconstriction but does not tell one whether bronchoconstriction is actually occurring, manifesting itself in attacks of asthma. Symptoms may improve or even disappear during adolescence yet the bronchi remain abnormally labile (Trefor Jones and Jones, 1966 ; Blackhall, 1970). Since changes in lability may persist into adult life, it was considered of

1Present address : Department of Child Health, University of Queensland, Royal Children's Hospital, Herston, Brisbane, Queensland 4029, Australia interest to assess the effect of age on the labile and fixed aspects of airways resistance.

\section{MATERIALS AND METHODS}

Two groups of asthmatic males were studied. Series A consisted of 25 subjects who had had the lability index measured two to seven years previously. A further measurement of lability index was made in these subjects and the results of the two estimations were compared.

Series B was made up of 22 adults who in childhood had had asthma which was sufficiently severe to warrant referral to hospital, and had well-documented childhood histories. From the information obtained from the case records it was possible to classify the severity of asthma in childhood using the following criteria :

Mild asthma: Six or less attacks per year, with complete recovery between attacks

Moderate asthma: More than six attacks per year, with complete freedom from symptoms between attacks apart from some nocturnal wheezing and wheezing on exercise

Severe asthma: More or less constant wheeze with super-added attacks.

Patients who were taking disodium cromoglycate or bronchodilator drugs were requested to omit these on the day of the test. Those on steroids were advised to continue these uninterrupted, as they have no 
influence on the labile component of airways resistance.

MEASUREMENT OF LABILITY INDEX This was carried out as described by Jones (1966). Forced expiratory volume in one second $\left(\mathrm{FEV}_{1}\right)$ was measured at rest, the mean value of three attempts after practice being used. The subject then exercised for eight minutes, exercise taking the form of running on a treadmill. The speed and incline of the treadmill were adjusted for each individual during the early part of exercise so that a level of exercise was achieved which would cause moderate breathlessness but which could be continued for the remainder of the period without causing undue stress. In this series, treadmill speeds ranged from 3.5 to 5.8 m.p.h. (mean 5.0, S.D. 0.6 ) and the slope varied from 0 to $7 \%$ (mean 3.1, S.D. 2.2) for series A subjects. The corresponding figures for series B were 4.0 to 5.8 m.p.h. (mean 5.2, S.D. $0 \cdot 38$ ) and 0 to $5 \%$ (mean 3.2, S.D. $1 \cdot 8$ ).

After this, the $\mathrm{FEV}_{1}$ was measured at two-minute intervals for a 10-minute period, and the lowest value obtained was noted. When the $\mathrm{FEV}_{1}$ had returned to normal, the subject inhaled isoprenaline sulphate 1\% administered by a Wright's nebulizer with an air flow of $101 /$ minute. The inhalation was given in three divided doses, spread over a five-minute period, for a total duration of two minutes. This was followed immediately by one minute's brisk exercise on the treadmill. Thereafter the $\mathrm{FEV}_{1}$ was recorded every minute till the maximum value was reached. Lability index was then calculated according to the formula :
Lability index $=\frac{\text { Fall in } \mathrm{FEV}_{1}+\text { Rise in } \mathrm{FEV}_{1}}{\text { Predicted normal FEV }} \times 100$

where fall in $\mathrm{FEV}_{1}=$ fall from resting level, rise in $\mathrm{FEV}_{1}=$ rise from resting level.

In subjects up to and including 18 years, predicted normal values used were those of Strang (1959). Over the age of 18 years, predicted normal values given by Cotes, Rossiter, Higgins, and Gilson (1966) were used.

By means of the lability index, asthmatic subjects were divided into groups 1,2 , and 3. Most normal subjects have values $<15 \%$ for lability index, though a few are in the range 15 to $20 \%$. Groups 1 and 2 have abnormally high values, an arbitrary subdivision being made between the groups at $30 \%$. It can be seen that there is some overlap between normal and group 1 subjects in that both contain a few individuals with values of 15 to $20 \%$. Group 3 subjects are separated off from the rest by their inability to achieve normal values for $\mathrm{FEV}_{1}$ on maximum bronchodilatation. In these, the fixed component of airways resistance predominates, obscuring to a varying degree the labile component.

Measurement of $\mathrm{FEV}_{1}$ was made using a closedcircuit spirometer specifically designed to be suitable for exercise studies, ${ }^{2}$ having a low resistance to gas flow, an interval air circulation rate of about 3001 / min, a large carbon dioxide absorption system, and

2Lode D51, available from Lode, Oosterstraat 38, Groningen, Holland

T A B LE I

RESULTS IN SERIES A

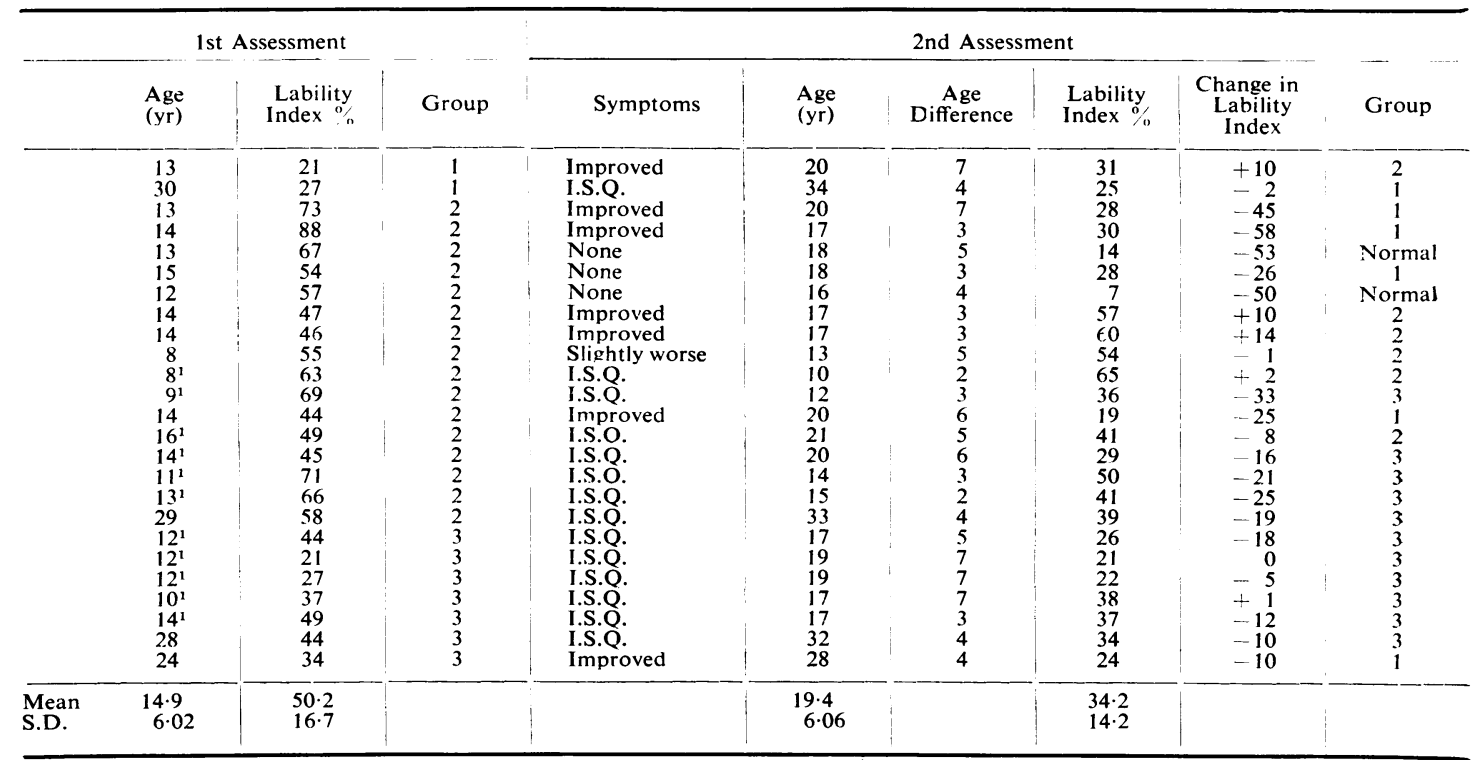

These patients were on steroid therapy at the time their lability index was measured. 
an efficient heat exchanger which kept circulating gas at room temperature.

FEV $V_{1}$ measured at ATPS was corrected to BTPS using the appropriate correction factor obtained from standard tables.

\section{RESULTS}

SERIES A At the original measurement of lability index the 25 subjects in this series were distributed as follows: 2 belonged to group 1, 16 to group 2, and 7 to group 3 (Table I). The mean age was 14.9 years, and the mean lability index $50.2 \%$.

At follow-up, the mean age of the patients in series A was 19.4 years. Three subjects were then free of symptoms, seven were improved, one had deteriorated slightly, while the remaining 14 were largely unchanged. The three who were symptomfree and five of those who were improved had originally belonged to group 2 . One subject from group 1 and one from group 3 showed clinical improvement. Thus, on clinical grounds, $50 \%$ of group 2 subjects showed improvement, whereas this rarely happened in group 3.

Changes in lability index were as follows: the mean lability index of the group had dropped to $34.2 \%$ over the course of 4.5 years. This difference is highly significant $(P<0.001)$. The group 1 subjects showed an increased lability in one case, the other being unchanged. Six subjects in group 2 were less labile, moving to group 1 or the normal range, five were still in this group, and five had deteriorated to group 3 . Thus $38 \%$ were improved, $31 \%$ were unchanged, and $31 \%$ were worse. Group 3 subjects remained in group 3 in all but one instance, where improvement to group 1 occurred.

The changes in lability index are shown in Fig. 1 where the index is broken down into its component parts of constriction and dilatation. The values of $\mathrm{FEV}_{1}$ at rest, on maximum constriction, and on maximum dilatation are expressed as percentages of the predicted normals. The means in each group at the first assessment are compared with the means at the second assessment. In groups 1 and 3 there is little change in lability. In group 2 , there is a considerable reduction in total lability, mainly due to a lessening of bronchoconstriction. The decrease in lability is even more striking when the six subjects who improved are considered separately (Fig. 2); a big decrease in post-exercise bronchoconstriction is apparent.

The movement from group 2 towards improvement or deterioration is shown in Table II, but the numbers involved are too small to allow satisfactory statistical analysis.

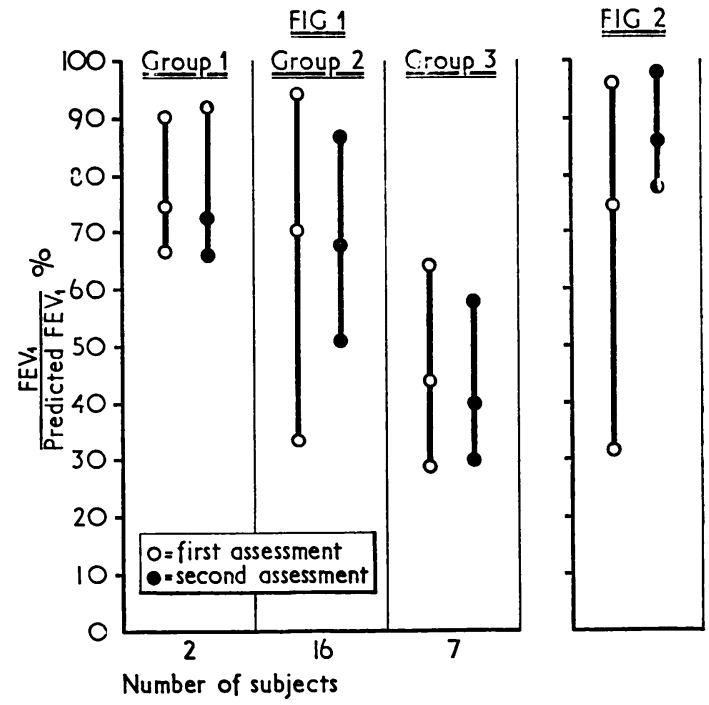

FIG. 1. Lability index of patients in series $A$ in each of the original groups at first and second assessments. Points indicate the FEV expressed as a percentage of the predicted value, with the value at rest in the centre, on dilatation at the top, and on constriction at the foot. The lability index is represented by the total length of the line.

FIG. 2. Lability index in six group 2 subjects from series $A$ who showed improvement at the second assessment.

T A B L E I I

CHANGES IN LABILITY INDEX AT 1ST AND 2ND ASSESSMENTS OF PATIENTS IN SERIES A

\begin{tabular}{c|c|c|c|c|c}
\hline \multicolumn{1}{c|}{ 1st Assessment } & \multicolumn{4}{|c}{ 2nd Assessment } \\
\cline { 2 - 6 } Group & Total & Normal & Group 1 & Group 2 & Group 3 \\
\hline 1 & 2 & & 1 & 1 & 5 \\
2 & 16 & 2 & 4 & 5 & 6 \\
\hline 3 & 7 & & 1 & & 6 \\
\hline Total & 25 & 2 & 6 & 6 & 11 \\
\hline
\end{tabular}

SERIES B The results in this group are summarized in Table III. The childhood histories of these 22 subjects showed that asthma was mild in five subjects, moderately severe in 10 , and severe in the remaining seven. The mean age on first attending hospital was 10.5 years.

At follow-up the mean age of the series was 28.1 years. Two of the mild cases were still mild and were in group 1 (lability indices 24 and 24). The remaining three mild patients were symptom-free, but only one of these had a completely normal lability index $(8 \%)$, the others being $19 \%$ and $17 \%$, which is in the range $(15 \%$ 
T A B L E I I I

RESULTS IN SERIES B PATIENTS

\begin{tabular}{|c|c|c|c|c|c|c|}
\hline \multicolumn{2}{|c|}{ Original Status } & \multicolumn{5}{|c|}{ Status at Follow-up } \\
\hline $\begin{array}{l}\text { Age } \\
\text { (yr) }\end{array}$ & Severity & $\begin{array}{l}\text { Age } \\
(y r)\end{array}$ & $\begin{array}{c}\text { Age } \\
\text { Difference }\end{array}$ & Severity & $\begin{array}{l}\text { Lability } \\
\text { Index \% }\end{array}$ & Group \\
\hline $\begin{array}{r}12 \\
11 \\
7 \\
12 \\
17 \\
6 \\
9 \\
5 \\
10 \\
13 \\
13 \\
13 \\
11 \\
14 \\
13 \\
14 \\
11 \\
6^{1} \\
9 \\
10^{1} \\
11^{1} \\
5\end{array}$ & $\begin{array}{l}\text { Mild } \\
\text { Mild } \\
\text { Mild } \\
\text { Mild } \\
\text { Mild } \\
\text { Moderate } \\
\text { Moderate } \\
\text { Moderate } \\
\text { Moderate } \\
\text { Moderate } \\
\text { Moderate } \\
\text { Moderate } \\
\text { Moderate } \\
\text { Moderate } \\
\text { Moderate } \\
\text { Severe } \\
\text { Severe } \\
\text { Severe } \\
\text { Severe } \\
\text { Severe } \\
\text { Severe } \\
\text { Severe }\end{array}$ & $\begin{array}{l}30 \\
30 \\
24 \\
27 \\
33 \\
22 \\
30 \\
22 \\
25 \\
26 \\
30 \\
30 \\
31 \\
28 \\
31 \\
35 \\
26 \\
26 \\
28 \\
30 \\
32 \\
23\end{array}$ & $\begin{array}{l}18 \\
19 \\
17 \\
15 \\
16 \\
16 \\
21 \\
17 \\
15 \\
13 \\
17 \\
17 \\
20 \\
14 \\
18 \\
21 \\
15 \\
20 \\
19 \\
20 \\
21 \\
18\end{array}$ & $\begin{array}{l}\text { Mild } \\
\text { Mild } \\
\text { Symptom-free } \\
\text { Symptom-free } \\
\text { Symptom-free } \\
\text { Symptom-free } \\
\text { Symptom-free } \\
\text { Mild } \\
\text { Mild } \\
\text { Mild } \\
\text { Mild } \\
\text { Mild } \\
\text { Mild } \\
\text { Moderate } \\
\text { Severe } \\
\text { Severe } \\
\text { Severe } \\
\text { Severe } \\
\text { Severe } \\
\text { Severe } \\
\text { Severe } \\
\text { Severe }\end{array}$ & $\begin{array}{l}24 \\
24 \\
19 \\
17 \\
8 \\
17 \\
28 \\
21 \\
25 \\
26 \\
21 \\
19 \\
23 \\
38 \\
40 \\
21 \\
30 \\
21 \\
29 \\
33 \\
21 \\
21\end{array}$ & $\begin{array}{c}1 \\
1 \\
\text { Normal } \\
\text { Normal } \\
\text { Normal } \\
\text { Normal } \\
1 \\
1 \\
1 \\
1 \\
1 \\
1 \\
1 \\
2 \\
3 \\
3 \\
3 \\
3 \\
3 \\
3 \\
3 \\
3\end{array}$ \\
\hline $\begin{array}{lr}\text { Mean } & 10.5 \\
\text { S.D. } & 3.1\end{array}$ & & $\begin{array}{r}28 \cdot 1 \\
3 \cdot 5\end{array}$ & & & $\begin{array}{r}23 \cdot 9 \\
7 \cdot 0\end{array}$ & \\
\hline
\end{tabular}

${ }^{1}$ These patients were on steroid therapy at the time their lability index was measured.

to $20 \%$ ) where there is overlap between normal subjects and asthmatics. Of those with mild symptoms $60 \%$ therefore showed improvement, the remaining $40 \%$ remaining mild.

The picture in the moderately severe subjects was as follows: two were symptomless, but one had a high normal lability index $(17 \%)$ and the other was abnormal (28\%). Six had mild symptoms, and all belonged to group 1 . One continued to have moderately severe symptoms and had a lability index of $38 \%$ (group 2). The tenth subject had developed severe symptoms and belonged to group 3 . Thus $80 \%$ of the group with moderate symptoms had improved. All the severe cases remained severe and belonged to group 3 on testing.

Our subjects with mild or moderate symptomatology had the best prognosis, and those with severe symptoms, almost without exception, remained severe.

\section{DISCUSSION}

Interest in the prognosis of childhood asthma has been considerable, as is shown by the numerous publications on the subject (Rackemann, 1928; Pearson, 1958; Bullen, 1929; Buffum and Settipane, 1966 ; Barr and Logan, 1964 ; Freeman and Johnson, 1964 ; Johnstone, 1968). Much useful information is available in these reports, but the variety of methods of classification used and the subjective assessment of improvement make the conclusions reached difficult to interpret.

Studies reported by Unger, Unger, and Wolf (1952) and Ogilvie (1962) suggest that subjects with intermittent attacks of asthma have a better prognosis than those with chronic wheezing. Subjects with intermittent attacks are likely to belong to groups 1 or 2 in the classification used here, while those with chronic wheezing are almost certain to be in group 3. Although this subdivision into 'intermittent' and 'continuous' wheezing seems to be a more useful approach to a satisfactory classification of severity of asthma, it lacks the objectivity offered by the Jones classification. The wide variation of other reported improvement rates in asthma (Bullen, 1929; Rackemann and Edwards, 1952 ; Dees, 1957 ; Ryssing and Flensborg, 1963 ; Barr and Logan, 1964 ; Buffum and Settipane, 1966) is doubtless a reflection of the fact that a classification based on clinical grounds alone is not altogether reliable.

The asthmatic subject's clinical symptoms depend upon the contribution to total airway resistance of the fixed and labile components, and some index of these two factors therefore aids the accurate assessment of the subject's condition. It is apparent from Table $I$ that improvement in symptoms does not necessarily imply reductions in lability - three subjects who on clinical grounds had improved (one originally in group 1, two in group 2), showed no corresponding decrease in 
lability. Of the eight subjects who were symptomfree at follow-up (three in series $A$ and five in series B), two were still abnormally labile, falling into group 1 ; three had high normal values, while only three were completely normal. Other stimuli apart from exercise may cause bronchoconstriction in the labile subject (e.g., pollens and psychological factors) and the occurrence of symptoms will depend on whether or not the subject encounters these stimuli

Symptoms may be prominent and troublesome, yet if they are primarily due to the labile component (as in the majority of childhood asthmatics, groups 1 and 2) the tendency is towards improvement. On the other hand, if symptoms are primarily due to the fixed component the tendency is towards persistence and deterioration (group 3). Thus, the group 2 asthmatic, with near normal resting levels of $\mathrm{FEV}_{1}$ but high lability of the bronchi, shows the greatest tendency to improve. The reason for this lessening of the labile component of airways resistance with age is not at present clear. Evidence points to post-exercise bronchoconstriction being mediated via the neuromuscular mechanism. Early work by Jones et al. (1963) has shown that sympatheticomimetic amines prevent the post-exercise fall in $\mathrm{FEV}_{1}$ but atropine and antihistamines do not. McNeill, Nairn, Millar and Ingram (1966) confirmed the prevention of post-exercise bronchoconstriction with sympatheticomimetic amines and demonstrated that repeated exercise tests on the same day lessened the degree of bronchoconstriction. They postulate that this is due to a depletion of constrictor substance. Disodium cromoglycate, a drug which blocks reagin-mediated type 1 hypersensitivity and, to a lesser extent, precipitin-mediated type 3 reaction (Cox, 1967), prevents the post-exercise fall completely or partially, but not in all subjects (Blackhall and Jones, 1969 ; Davies, 1968 ; Palmer and Legge, 1969). Propranolol, a $\beta$-adrenergic blocking agent, increases the fall in $\mathrm{FEV}_{1}$ in asthmatic subjects (Jones and Blackhall, unpublished) and may in some normal subjects cause an increased post-exercise fall. With further elucidation of the mechanism of bronchoconstriction it may become clear why the labile component of airways resistance decreases with age. Its persistence in many after symptoms have ceased (Trefor Jones and Jones, 1966 ; Blackhall, 1970 ) is also unexplained.

The fixed component, on the other hand, tends to remain or increase with age, as shown here by the group 3 cases who show some lowering of resting $\mathrm{FEV}_{1}$ and lessening of ability to dilate with bronchodilator drugs and short exercise. The fact that some subjects do improve is evidence that this process may not be inevitably irreversible. Airways obstruction in group 3 subjects appears to be determined by inflammatory reaction in the mucosa and by outpouring of mucus causing luminal obstruction to a greater extent than by the muscular factor. The outcome will therefore depend on the extent to which permanent changes in the mucosa have occurred.

I wish to thank Professor J. D. Hay for making available to me the facilities of the Department of Child Health, Dr. R. S. Jones for advice and encouragement, Professor C. A. Clarke for permission to study his patients, and Mrs. S. Dulson for technical assistance.

This work was supported by a Research Fellowship from the Department of Child Health, University of Liverpool, augmented by a grant from the Children's Research Fund.

\section{REFERENCES}

Barr, L. W., and Logan, G. B. (1964). Prognosis of children having asthma. Pediatrics, 34, 856.

Blackhall, M. I. (1970). Ventilatory function in subjects with childhood asthma who have become symptom free. Arch. Dis. Childh., 45, 363.

- and Jones, R. S. (1969). Effect of disodium cromoglycate on post exercise bronchoconstriction in asthma. Proceedings of Symposium on Disodium Cromoglycate in Allergic Airways Disease. Royal Society of Medicine, London, March 5, 1969. Butterworth.

Buffum, W. P., and Settipane, G. A. (1966). Prognosis of asthma in childhood. Amer. J. Dis. Child., 112, 214.

Bullen, S. S. (1929). Some observations on the natural history of asthma in childhood. N.Y. St. J. Med., 29, 545.

Cotes, J. E., Rossiter, C. E., Higgins, I. T. T., and Gilson, J. C. (1966). Average normal values for the forced expiratory volume in white Caucasian males. Brit. med. J., 1, 1016.

Cox, J. S. G. (1967). Disodium cromoglycate (FPL 670) ('Intal'): a specific inhibitor of reaginic antibodyantigen mechanisms. Nature (Lond.), 216, 1328.

Davies, S. E. (1968). Effect of disodium cromoglycate in exercise-induced asthma. Brit. med. J., 3, 593.

Dees, S. C. (1957). Development and course of asthma in children. Amer. J. Dis. Child., 93, 228.

Freeman, G. L., and Johnson, S. (1964). Allergic diseases in adolescents. II. Changes in allergic manifestations during adolescence. Amer. J. Dis. Child., 107, 560.

Johnstone, D. E. (1968). A study of the natural history of bronchial asthma in children. Amer. J. Dis. Child., 115, 213.

Jones, R. S. (1966). Assessment of respiratory function in the asthmatic child. Brit. med. J., 2, 972.

- Wharton, M. J., and Buston, M. H. (1963). The place of physical exercise and bronchodilator drugs in the assessment of the asthmatic child. Arch. Dis. Childh., 38, 539. 
McNeill, R. S., Nairn, J. R., Millar, J. S., and Ingram, C. C. (1966). Exercise-induced asthma. Quart. J. Med., 35. 55.

Ogilvie, A. G. (1962). Asthma: a study in prognosis of 1,000 patients. Thorax, 17, 183.

Palmer, K. N. V., and Legge, J. S. (1969). Disodium cromoglycate in exercise-induced asthma. Lancet, 2, 219.

Pearson, R. S. B. (1958). Natural history of asthma. Acta allerg. $(K b h), 12,277$.

Rackemann, F. M. (1928). Studies in asthma. Arch. intern. Med., 41, 346.

- and Edwards, M. C. (1952). Asthma in children: A. follow-up study of 688 patients after an interval of 20 years. New Engl. J. Med., 246, 815.
Ryssing, E., and Flensborg, E. W. (1963). Prognosis after puberty for 442 asthmatic children examined and treated on specific allergologic principles. Acta paediat. (Uppsala), 52, 97.

Strang, L. B. (1959). The ventilatory capacity of normal children. Thorax, 14, 305.

Trefor Jones, R. H., and Jones, R. S. (1966). Ventilatory capacity in young adults with a history of asthma in childhood. Brit. med. J., 2, 976.

Unger, L., Unger, A. H., and Wolf, A. A. (1952). Bronchial asthma in children: treatment and results. A thirty year study. Ann. Allergy, 10, 574. 